\title{
ESQUEMA DE COMUNICAÇÃO SOB OLHARES DA SEMIÓTICA E DA TECNOLOGIA ADAPTATIVA
}

\section{COMUNICATION SCHEMA UNDER SEMIOTICS AND ADAPTATIVE TECHNOLOGY OVERVIEW}

AnA CRISTINA FRICKe MATTE*

RESUMO: Este artigo busca discutir uma possível interface entre a semiótica greimasiana e a Tecnologia Adaptativa proposta por Neto (2000). O esquema de comunicação de Silva (1972) foi o ponto de partida para a definição de regras que permitissem a geração automática de diálogos baseada no conteúdo semiótico. A geração automática de diálogos envolve muitos campos da área de Letras e Linguística, sendo um dos maiores problemas enfrentados pelos que trabalham em automatização de interações homem-máquina. 0 esquema é apropriado, pois baseia-se num processo dinâmico de comunicação no qual o destinador e o destinatário são responsáveis por constantes ajustes, tornando o sistema um forte candidato para um esquema adaptativo da comunicação.

PALAVRAS-CHAVE: Semiótica. Esquema de comunicação. Padrões dinâmicos. Conteúdo. Robô. Chat.

* Docente da UFMG - Universidade Federal de Minas Gerais. E-mail: anacrisfm@ufmg.br. 
ABSTRACT: This article seeks to discuss the interface between Greimasian semiotics and Adaptive Technology, as proposed by Neto (2000). Silva's (1972) communication scheme is presented as a starting point for rules allowing the automatic generation of dialogues based on the semiotic content. The automaticgeneration of dialogues involves many fields belonging to Languages and Linguistics. This fact is one of the biggest problems faced by those working in the automation of human-machine interactions. The scheme is appropriate for allowing a dynamic communication process in which the sender and the receiver are responsible for constant adjustments, making the system a strong candidate for an adaptive communication scheme.

KEYWORDS: Semiotics. Communication scheme. Dinamic patterns. Content. Robot. Chat.

\section{Introdução}

Este trabalho traz parte de uma pesquisa em andamento sobre a construção de um robô para atendimento on-line de professores para uso de recursos educacionais on-line livres, o projeto Livrinho ${ }^{1}$.

A semiótica greimasiana é uma teoria com importante potencial de aplicabilidade interdisciplinar, como mostram trabalhos em diferentes áreas do conhecimento, especialmente na área das Ciências Humanas. 0 esquema de comunicação de Ignacio Assis Silva (BARROS, 2002), aqui focalizado, é mais um processo que um esquema, pois permite visualizar os deslizes presentes e intrínsecos ao fazer comunicativo, no lugar das estabilidades.

1 <http://www.sourceforge.net/projects/livrinho/>. Desenvolvimento: Grupo Texto Livre: Semiótica e Tecnologia, cadastrado no Diretório de Grupos do CNPq desde 2005. 
Considerando que a adaptatividade é a capacidade de um programa automodificar-se para atender a situações inicialmente não previstas em suas regras (NETO, 2000), estamos estudando esse esquema de comunicação como base para a introdução da adaptatividade no projeto Livrinho, especialmente no que diz respeito à geração automática de diálogos escritos. 0 trabalho de Alfenas e Pereira-Barretto (2012) é um forte indicativo da produtividade da utilização da Tecnologia Adaptativa para gerenciamento de diálogos.

A capacidade de automodificação, em essência, busca simular a habilidade humana de adaptar-se a diferentes situações a fim de obter um mesmo resultado.

Numa situação controlada, como o texto de uma notícia de jornal ou uma fábula, nos quais começo, meio e fim estão dados a priori, a análise semiótica, por sua vez, pode tomar o texto como um todo e, a partir deste todo, realizar sua análise, que acaba sendo - em virtude dessa característica finita previamente selecionada - de natureza discreta mesmo no que tange a elementos contínuos da construção do sentido. A análise de diálogos espontâneos, no entanto, foge a este controle e exige um tratamento não só menos linear da sequência discursiva, como também mais maleável no que diz respeito ao "todo" que define o texto, já que este muda a cada nova intervenção.

Este problema, fascinante para a semiótica, a nosso ver é o mesmo problema básico da adaptatividade quando trabalha com problemas complexos, com entrada de dados de um conjunto finito mas com infinitas possibilidades de resultados finais a partir de infinitas possíveis relações, já que o tamanho máximo do resultado é ilimitado.

A proposta de Silva transforma o famoso esquema de comunicação de Roman Jakobson (1969) em um processo di- 
nâmico, envolvendo o código - no caso, a língua -, o sinal - no caso, a escrita -, e o conteúdo semiótico - no caso, a construção do sentido na conversação no chat -, sendo particularmente adequado para tratar do problema aqui apresentado.

0 presente artigo está organizado em oito partes. Em "Semiótica e Tecnologia Adaptativa" busca-se apresentar a viabilidade desse diálogo teórico para pesquisadores de ambas as áreas, por suas semelhanças. "Um pouco de história" referenda o tópico anterior com base na história da interface entre a Semiótica e a Inteligência Artificial. "Comunicação pelo viés de Ignacio Assis Silva" discute o esquema proposto pelo pesquisador. 0 tópico "À guisa de metodologia" trabalha no sentido de prover ao esquema de comunicação ferramentas para sua aplicação prática na interface entre os estudos da linguagem e a computação. Os exemplos 1 a 4 (tópico "Exemplos") procuram aplicar, de forma breve, essa metodologia, embora ainda insipiente, em textos com diferentes problemas de ambiguidade. Finalmente, o tópico "Análise preliminar de identidade no chat" apresenta alguns exemplos de análise de chat numa abordagem preliminar do que seria a aplicação adaptativa deste esquema de comunicação. A conclusão traz uma síntese do artigo, com foco na concepção do esquema aqui discutido como proposta para um esquema adaptativo de comunicação.

\section{Semiótica e tecnologia adaptativa}

A semiótica greimasiana sempre esteve no limite entre a linguagem e a tecnologia, limite mesmo da ciência e do fazer científico, sendo uma teoria da linguagem sempre pronta a disputar lugar de destaque nos campos interdisciplinares e na pesquisa de ponta. Sua base estruturalista, embora seja 
alvo de inúmeras críticas por defensores de teorias concorrentes na área de Humanas, é, a nosso ver, um dos principais motivos pelos quais esta semiótica é altamente favorável a estudos interdisciplinares, inclusive com a área de Exatas (MATTE; LARA, 2009).

Trabalhando com uma separação metodológica entre imanência e manifestação, entre conteúdo e expressão e entre forma e substância, conceitos caros a Hjelmslev (1968), a análise semiótica busca apreender o sentido em imanência, nas profundidades, e jogá-lo de forma organizada para a superfície. Seu grande sucesso na literatura e em outras artes devese ao fato de que sua metalinguagem permite redimensionar o objeto analisado de forma quase tão artística quanto ele próprio foi construído, o que acaba muitas vezes "borrando" a imagem inicial, não porque a semiótica não possa ser nítida, mas porque o sentido é mais complexo do que aparenta na superfície. Assim, muitos trabalhos de análise semiótica acabam sendo, eles mesmos, quase que novas obras artísticas, no sentido em que a arte, para dar sentido ao mundo, reescreve seus eventos. Disso podem decorrer, e em alguns casos é efetivamente o que acontece, análises que, em escopos teóricos não literários, parecem visões distorcidas desse mundo, como por uso de óculos imperfeitos (o que não é necessariamente um desmérito da obra).

Esse modo de trabalhar com semiótica, portanto, não é o mais apropriado para trabalhos interdisciplinares, especialmente quando se trata da interface com ciências ditas mais duras. Nesse caso, pensamos, o melhor processo é o que, a partir de um palpite teórico baseado na semiótica e seguindo a metodologia semiótica à risca, vai desconstruir o texto de forma organizada, esvaziando-o de suas camadas mais superficiais em busca dos traços, daquilo que gostamos de chamar 
de caricaturas, pelo caráter mimético e por sua maleabilidade como meta objeto, permitindo que um texto seja compreensível por pessoas diferentes com histórias diferentes e, portanto, por pessoas com diferentes construções do que seja a própria linguagem. Trata-se da mesma ideia que, em 1995, buscou Silva (1995) no conceito de boi mínimo, retratado em "Metamorfoses de um touro" por Pablo Picasso: trata-se de buscar a humanidade e a civilidade mínimas, as quais acabam osciland o fortemente entre o inteligível e o sensível, ponto nevrálgico e forte da teoria semiótica. 0 tema foi bastante bem abordado por Silva (1995), com uma síntese completa no capítulo "Balizas".

\section{Um pouco de história}

A relação entre Semiótica e Inteligência Artificial foi primeiramente abordada em alguns trabalhos publicados na série Bulletin (hoje continuada pelo periódico Actes Sémiotiques), na década de 80 , especialmente em dois números dedicados ao tema: "Intelligence artificielle et théorie sémio-linguistique" (STOCKINGER et al., 1985) e "Intelligence Artificielle, II: Approches cognitives du texte" (STOCKINGER et al., 1986). Naqueles trabalhos, no entanto, a abordagem do tema foi bastante indireta: em parte porque alguns artigos deslizaram da semiótica para as ciências cognitivas ao realizar a análise da Inteligência Artificial, e em parte porque, quando deram maior destaque à semiótica propriamente dita, optaram por focalizar a relação homem máquina que estaria sendo simulada nos artefatos de Inteligência Artificial, de forma insipiente na época.

0 acompanhamento da bibliografia produzida desde então indica uma espécie de abandono dessa interface, que 
nos parece tão produtiva. Este abandono pode ser explicado em virtude da insipiência de ambas as teorias na década de 80. A semiótica data do início dos anos 70 e, na década de 80 , começava a trabalhar com problemas relativos às paixões, enquanto a Inteligência Artificial apenas começava a passar da fase de promessas para uma fase de realizações, ainda limitadas em termos de aplicação prática pelo baixo poder de processamento dos computadores na época. Os dois volumes do Bulletin, citados acima, são reflexo claro desse quadro.

0 que nos trouxe a esse palco foi uma pesquisa iniciada no doutorado na USP (MATTE, 2002) e continuada em pósdoutoramento na UNICAMP (MATTE, 2004a) sobre expressão da emoção na fala. Do ponto de vista semiótico², a emoção não é um conteúdo, é uma "expressão comprometida por uma paixão". Para a semiótica, paixão é um conjunto, passível de moralização, de modalizações e comportamentos de um sujeito, os quais destoam do quadro de valores socialmente aceito, incluindo ódio, amor, desejo de vingança e compaixão, dentre muitas outras. Assim, para explicar emoção com outras palavras: quando uma paixão qualquer afeta um sujeito, sua textualização reflete isso e é esse "afetar" o que define a emoção como uma perturbação corporal perceptível (voz trêmula, por exemplo). A emoção, portanto, é quantificável e pode ser medida se for observada em relação àquele padrão socialmente aceito, como é o padrão linguístico, por exemplo.

Os principais resultados dessa pesquisa de pós-doutoramento são: i) uma proposta de medida do que chamamos Modalização Temporal Tensiva (reflexo da emoção no texto, em qualquer linguagem) (MATTE, 2004b), ii) um método para identificar e descartar amostras afetivamente comprometidas

2 Adotamos aqui a teoria como apresentada em Semiótica das paixões, de Greimas e Fontanille (1993). 
no sinal acústico, a fim de tornar o corpus adequado ao padrão linguístico de referência (MATTE, 2008) e, finalmente, iii) um software para trabalho em fonética acústica, o Setfon (MATTE; MEIRELES; RIBEIRO, 2011).

Muitas vezes, durante nosso trabalho na interface com a fonética acústica, em busca de desvelar os mecanismos de produção de sentido emotivo na fala, a Inteligência Artificial foi cogitada como parceira alternativa para os estudos semióticos da comunicação, mas somente no WTA2012 encontramos, na Tecnologia Adaptativa, o tipo de abordagem que, acreditamos, seja o adequado para o tipo de análise que aqui se quer fazer.

A Tecnologia Adaptativa, como comentado na introdução (ALFENAS; PEREIRA-BARRETTO, 2012), visa à modificação de regras, em softwares, num sistema quase minimalista baseado em operações de inclusão, remoção e consulta. Essa ideia de uma sintaxe básica e abstrata, a qual garante a aplicação da TA a diferentes linguagens e sistemas computacionais (NETO, 2003 e 2007), é comparável à forma como a semiótica trabalha sua própria sintaxe, especialmente no nível narrativo, no qual as relações são de natureza lógica. 0 nível narrativo possui uma estrutura bastante cristalizada, pois foi o primeiro a ser desenvolvido, e a forma de organizá-lo e compreendê-lo, dada essa anterioridade, afeta a forma com que são abordados os outros níveis de produção do sentido.

Respeitadas as diferenças das linguagens-objeto com que trabalham a Semiótica e a Tecnologia Adaptativa, em ambas as teorias a sintaxe mínima aparece e multiplica-se em cada objeto, não só em extensão, como também em diferentes instâncias (níveis ou camadas), aumentando a complexidade do sistema sem, no entanto, causar uma multiplicação desnecessária e indesejável das unidades sintáticas mínimas. 


\section{Comunicação no viés de Ignacio Assis Silva}

A análise da construção do sentido pela semiótica possui, atualmente, um arsenal de recursos analíticos coeso e suficientemente amplo para dar conta dos mais diferentes objetos e linguagens, no que tange à construção do sentido. Assim, a teoria passou a ocupar-se de problemas para os quais não havia, inicialmente, fundamentação suficiente para sua abordagem, apesar de previstos desde o princípio das investigações semióticas. Trata-se de questões como continuidade, plano da expressão, percepção e, o que nos interessa aqui, a comunicação em processo.

Os esquemas de comunicação, na grande maioria, pecam por manterem-se fiéis àquilo que se propõem ser, pois um esquema não precisa descrever a dinâmica do processo. Um esquema pode ser como uma foto, estática, e a grande maioria dos esquemas de comunicação segue esse estilo (KLINKENBERG, 2009). É justamente por explorar o caráter dinâmico do processo comunicativo que o esquema de Ignacio Assis Silva é uma dentre as opções mais adequadas à análise da comunicação. Neste artigo apresentamos alguns exemplos dessa dinâmica tendo em vista o estudo de regras relativas ao conteúdo do texto para geração automática de diálogos, na interface entre a Semiótica e a Tecnologia Adaptativa.

O esquema de comunicação aqui focalizado (Figura 1), que parte do conjunto Destinador (formado por fonte, mensagem como imagem e transmissor) e Destinatário (formado por receptor, mensagem como imagem e destino) foi proposto por Ignacio Assis Silva em sua tese de doutorado (SILVA, 1972), e reapresentado por Diana Barros no livro Introdução à Linguística publicado pela FFLCH/USP (BARROS, 2002). Imagem, aqui, possui o mesmo sentido que "imagem acústica" 
em Saussure (1969) e Câmara Jr. (2002a).

Figura 1 - Esquema de comunicação de Silva (1972).

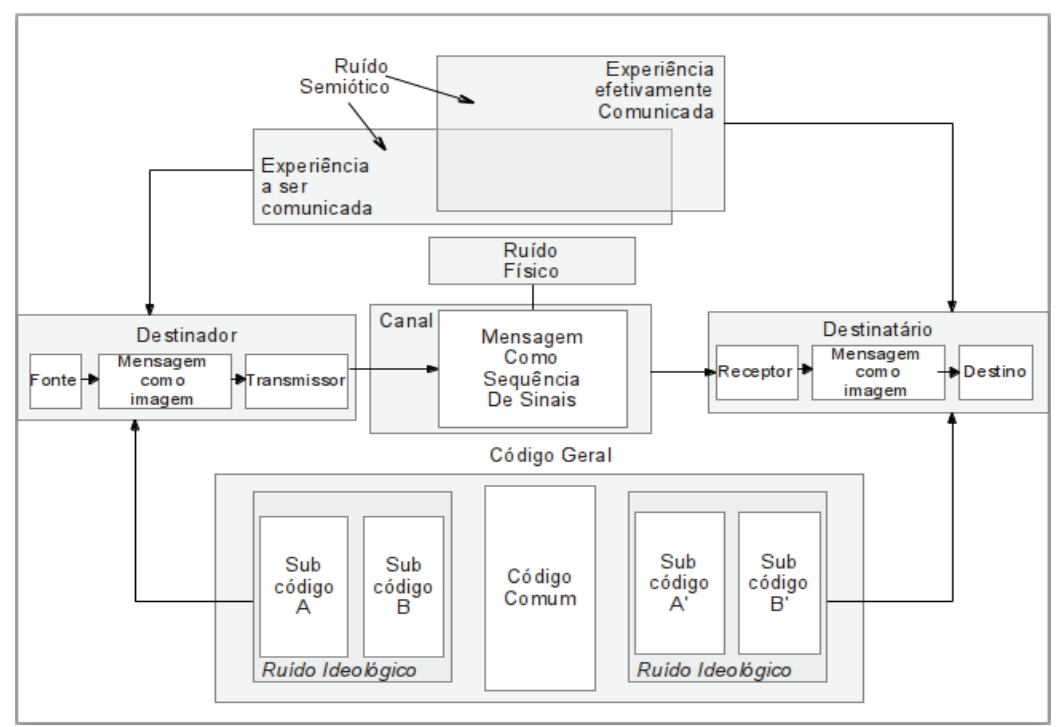

Em Matte (2008), analisamos o esquema passando a nomear as três vias de construção da comunicação: a via do código, a via do sinal e a via semiótica. Naquele artigo, discutimos o conceito de "ruído", que é nada mais do que uma diferença potencial entre o que cada actante do processo comunicativo (Destinador e Destinatário) institui para cada texto em cada uma das vias. 0 ruído, que já fazia parte da proposta inicial de Silva, é o responsável pela dinâmica do processo: é exatamente porque cada actante sabe que existe um ruído intrínseco em cada uma das vias que a comunicação é possível.

Assim, pode-se afirmar que existem dois sistemas em choque, produzindo um terceiro, que é o da comunicação em si.

0 primeiro sistema é do Destinador e é formado pela mensagem que ele deseja comunicar, pelo seu conhecimento 
do código, pela imagem que faz do código do destinatário e, finalmente, pela capacidade de produzir o sinal necessário no processo de textualização, no caso dos nossos exemplos, produzir a escrita ou a fala e transmiti-la ao Destinatário.

É importante notar que esse esquema, embora concebido inicialmente para a fala, não predetermina nem o tipo de suporte para o envio do sinal e nem a linguagem utilizada. No caso da presente pesquisa sempre estamos trabalhando com a linguagem verbal escrita, o que significa que o código é verbal e o sinal é visual e digitalizado.

O segundo sistema é o do Destinatário, que, sem esperarmos que se trate de um processo linear, recebe o sinal, decodifica-o e interpreta o sinal decodificado. Esse sistema é formado, portanto, pela capacidade de receber o sinal, pelo seu conhecimento do código, pela imagem que tem do código usado pelo Destinador e pela possibilidade de preencher as lacunas inerentes à mensagem recebida.

A via do código (a primeira de baixo para cima na Figura 1) é a via da língua, no caso de linguagens verbais, e o ruído pode aparecer desde sutis diferenças individuais na conceitualização do vocabulário até diferenças entre as línguas dos falantes. 0 ruído produzido pela diferença entre o que o Destinador pensa ser o sub-código do Destinatário (e que define o padrão linguístico adotado por ele) e o que o Destinatário pensa ser o sub-código utilizado pelo Destinador (que é sua referência para decodificação) é chamado de ruído ideológico (Figura 2) por Silva. 
Figura 2 - Ruído na via do código, no esquema de Silva (1972).

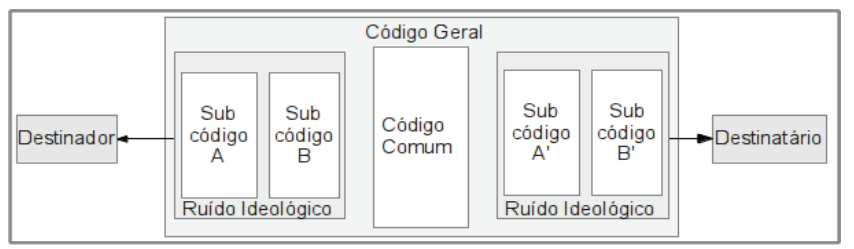

A via do sinal (representada como central no esquema) é a do plano da expressão. No caso da língua (linguagem verbal), pode tanto ser sonora (fala) quanto visual (escrita). 0 ruído que afeta essa via é o ruído físico (Figura 3), podendo ser uma má dicção, uma caligrafia problemática, o ruído no telefone e até problemas de conexão causando perda de sinal.

Figura 3 - Ruído na via do sinal, no esquema de Silva (1972).



Silva, ainda nos primórdios da semiótica greimasiana, não chegou a aprofundar a última via, a via semiótica (nomeada segundo a proposta de Matte, 2008), na qual o elemento chave é a experiência. Existe uma diferença intrínseca entre o que se quer dizer e o que se diz de fato, em qualquer processo comunicativo, por inúmeros fatores que não cabem no 
escopo do presente artigo. Podemos explicar de forma resumida essa diferença intrínseca pelo que decidimos chamar de

\section{lacunas.}

As lacunas são inerentes ao processo de comunicação, no que tange à via semiótica do esquema. Podemos apoiar essa hipótese num exemplo bastante corriqueiro: como se consegue contar um filme que dura duas horas? Deixando elementos fora da narração. Escolhemos para omitir os elementos que, supomos, possam ser facilmente recuperados pelo Destinatário o qual, por sua vez, sabe que sempre receberá uma "pintura incompleta" e precisará "pintar por conta própria" boa parte da "tela" a fim de obter o quadro completo. A semiótica explica o sucesso deste processo pela existência de uma cadeia de pressupostos e pressuponentes disponíveis como pistas para tal preenchimento nos três diferentes níveis do percurso gerativo do sentido. Isso evita situações problemáticas como um Destinador que decidisse contar um filme em todos os detalhes (além da história, temos música, iluminação, perfil dos personagens, ritmo das cenas, cores, formas, tomadas de câmera etc.), levando, assim, não duas horas, mas dois anos para terminar a narração, o que é humanamente inapropriado, para dizer o mínimo.

Assim, é imprescindível que, para comunicar qualquer experiência, sejam deixadas lacunas, não importa a linguagem e nem o suporte utilizados. Pode-se afirmar que parte da própria competência do Destinador é determinada por sua capacidade de escolher as lacunas corretas a serem deixadas para ser preenchidas pelo Destinatário.

Ao efeito das lacunas sobre o processo de comunicação optamos por designá-lo como ruído semiótico (Figura 4), já que trata do conteúdo da comunicação. 
Figura 4 - Ruído na via semiótica do esquema de Silva (1972).

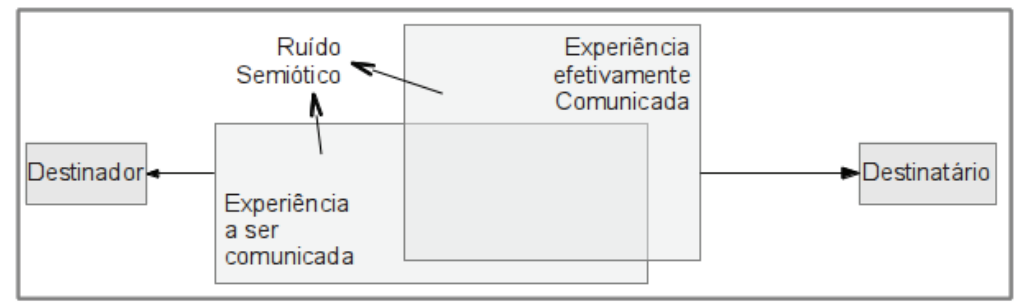

Em todas as vias, portanto, temos um ruído correspondente intrínseco e até necessário como parte do conjunto esperado:

- Via semiótica $\rightarrow$ ruído semiótico: causado pela diferença entre o que foi omitido na mensagem pelo Destinador e o que foi utilizado pelo Destinatário para preencher as lacunas deixadas por essa omissão - intencional ou não (Figura 4);

- Via do sinal $\rightarrow$ ruído físico: causado pela perturbação provocada no plano da expressão por falhas na transmissão, impropriedade do suporte físico e/ou habilidade limitada dos actantes (Figura 3);

- Via do código $\rightarrow$ ruído ideológico: causado pela interseção entre dois conjuntos de códigos com um código geral. 0 conhecimento do código geral por ambos os actantes é o que permite a comunicação, embora sua falta não resulte necessariamente em sua interrupção e o código comum aos dois nunca seja igual à totalidade do código geral; além disso, cada actante conta com uma variante pessoal do código e uma suposição do que seja a variante do outro actante. A intersecção da variante pessoal de cada actante com a variante suposta pelo outro produz o ruído ideológico (Figura 2).

0 ruído, em qualquer das três vias, varia em grau e intensidade, desde o imperceptível, quando não causa nenhum efeito importante e, assim, não requer nenhuma adaptação, 
até o insuportável, quando nenhuma adaptação possível pode restaurar o fluxo comunicativo e a comunicação é interrompida.

Ousamos mesmo afirmar que se trata de um sistema adaptativo por natureza, já que pode ser descrito como um sistema baseado em regras e passível de automodificação pela inclusão ou remoção previsível de regras. Transições adaptativas são adequadas a qualquer uma das etapas visíveis na Figura 1, para além mesmo dos ruídos previstos por Silva (1972):

\section{No Destinador:}

- da "fonte" à "mensagem como imagem";

- da "mensagem como imagem" ao "transmissor";

2. Do Destinador ao Destinatário pela via do sinal:

- do "transmissor" à "mensagem como sequência de sinais";

- na relação entre a "mensagem como sequência de sinais" com o "canal" (suporte físico da textualização);

- da "mensagem como sequência de sinais" ao "receptor";

3. Do Destinador ao Destinatário pela via do código:

- da "mensagem como imagem" ao "código do destinador";

- da "mensagem como imagem" ao "código do destinatário";

- do "código do destinador" ao "código do destinatário suposto pelo destinador";

- do "código do destinatário suposto pelo destinador" ao "código do destinatário";

- do "código do destinador" ao "código do destinador suposto pelo destinatário";

- do "código do destinador suposto pelo destinatário" ao "código do destinatário";

4. Do Destinador ao Destinatário pela via semiótica: 
- da "mensagem original" à "mensagem com lacunas";

- da "mensagem com lacunas" à "mensagem preenchida";

• da "mensagem original" à "mensagem preenchida".

O esquema de Silva pressupõe que qualquer comunicação seja afetada por ruído, variando apenas o grau ou intensidade com que esse ruído afeta o processo. Desse modo, toda comunicação é sempre um processo de adaptação entre os actantes, explicando os ajustes constantes realizados pelas partes envolvidas durante todo o evento comunicativo.

Também é possível explicar, assim, a preferência histórica da semiótica pelos objetos "acabados", tais como notícias de jornais ou romances, pois um dos actantes (o Destinador) passa a pressuposto, não sendo mais acessível senão por marcas deixadas no texto (marcas da enunciação) e que, enquanto marcas, são estáticas. Desta forma, apenas um dos lados do esquema permanece sujeito às oscilações causadas pelo ruído.

Mas o que nos interessa não é esse tipo de objeto: o objetivo do estudo, cujos pressupostos estão sendo discutidos no presente artigo, é a comunicação em processo, sincrônica e sujeita a ruídos constantes e ajustes provenientes de todos os participantes, sejam eles Destinador ou Destinatário.

Compreendemos o ruído como o espaço para aplicação da Tecnologia Adaptativa no esquema, escolhido para abordar essa comunicação em processo: não é o código ou o sinal ou a mensagem o foco das modificações, mas o desequilíbrio causado pelas duas forças em jogo, a de quem comunica e a de quem interpreta.

\section{À guisa de metodologia}

Na interface entre a análise textual computadorizada e 
a análise semiótica, enfrentamos um problema que não pode ser resolvido senão de forma arbitrária. Para o computador, o texto completo não pode ser a unidade mínima. Para a semiótica, por outro lado, o texto é um todo dotado de sentido e qualquer quebra provoca mudanças no sentido produzido. A fim de buscar um equilíbrio, optamos por dividir o texto em sentenças, pois cada uma possui um sentido próprio, mas sem perder de vista que esse sentido depende do texto como um todo (MATTE et al., 2012).

Acontece que, mesmo para o esquema de Silva, cada uma das vias pede uma divisão diferente do texto-objeto.

A análise da frase termo a termo geralmente não é a mais adequada para a análise do ruído semiótico, pois as lacunas aparecem em trechos muitas vezes maiores do que a frase, compreendendo o texto inteiro. Em outras palavras, sendo o sentido dado no texto como um todo, uma análise termo a termo não seria adequada porque não seria capaz de recuperar a informação total do texto, nem aquela que se quer dizer nem aquela que se pode apreender. 0 sentido do texto não é dado pela soma de suas partes.

Mesmo se comparadas a via do sinal e a via do código, trata-se de duas unidades mínimas de análise de dimensões bem diferenciadas, seja qual for a linguagem em foco. No caso da língua verbal falada, por exemplo, a unidade mínima do sinal é a sílaba, enquanto, no nível do código, são termos muitas vezes do tamanho de palavras, seja do ponto de vista semântico, seja do ponto de vista sintático.

Como realizar, então, o cruzamento de três vias de comunicação cujas unidades mínimas não coincidem?

Pensamos ser necessário determinar um modelo de análise, o que geralmente é feito pelo caminho indutivo, com uma pesquisa de casos, antes da proposição de um modelo. 
No entanto, ao se tomar a teoria semiótica como ponto de partida, essa limitação muda, pois a teoria permite adotar uma postura dedutiva. Propomos que o ponto de vista seja a narrativa, berço das principais lacunas necessárias ao fazer comunicativo e que, por sua natureza lógica, não possui uma ligação direta com a textualização, que é, em última análise, uma junção de escolhas no código que só são manifestadas pela produção de um sinal específico. Ou seja, o nível narrativo seria o mais próximo da imanência e, desta forma, o menos afetado pelas outras duas vias do processo comunicativo, as quais estão intimamente ligadas à textualização.

Temos assim uma possibilidade de análise que vai partir da semiose para a textualização e da imanência à manifestação. Esse processo é o processo básico da geração de diálogos, do evento da comunicação em si: a rigor, o algo a ser dito pré-existe ao dito, que está pressuposto pela interpretação do dito.

Uma situação interessante para pensar esse processo seria justamente o oposto. Num jogo de formação de palavras a partir de letras, por exemplo, o sinal existe antes do código e este existe antes do sentido. Será? Semioticamente falando, o primeiro código em andamento é o do próprio jogo, cujas peças e regras criam um sistema cujo sentido final é o sentido de vencedor e perdedor - e, afinal, uma linguagem é um sistema para produzir um sentido. Nesse caso, não existiria nesse exemplo o processo oposto, mas isso não significa que o processo não exista.

Fizemos questão de levantar um aparente exemplo para mostrar uma das características essenciais do esquema processual de comunicação que estamos utilizando: ele baseia-se na premissa semiótica de que o homem é um animal imerso na linguagem e só tem acesso ao mundo por meio da linguagem e é com base nessa premissa que vamos analisar o exemplo seguinte. 
As nuvens no céu formam desenhos que ninguém desenhou. Não existe um Destinador, como pensar, nesse caso, em comunicação? Toda a teoria semiótica baseia-se numa tendência do homem em ver o mundo como espelho, antropomórfico e antropocentrado. Como se pode depreender de Klinkenberg (2009), qualquer reta na qual o sujeito apareça como um ponto será, para ele, sempre uma reta que para ele aponta ou dele sai. É um sentido primário da própria narratividade, em que o sujeito é sempre centro.

Assim, não importa se existe ou não um Destinatário das nuvens, se o ator não ocupa o papel de Destinador, ele vai se colocar na outra posição, a de Destinatário, automaticamente, ficando o Destinador, se não aparente ou explícito, simplesmente pressuposto. Então, qualquer configuração que se encaixe, mesmo por acaso, em alguns dos códigos dominados pelo ator "leitor do mundo" (ou códigos nos quais está imerso), vai ser vista como uma manifestação textual e, portanto, manifestação geradora de sentido. É assim que a criança enxerga cachorros e flores em milho de pipoca estourado, de forma aparentemente aleatória.

Em primeiro lugar, é necessário lembrar que, embora o esquema de comunicação de Silva seja adequado a qualquer linguagem, para os fins do presente trabalho a linguagem é sempre verbal, na modalidade escrita.

A cadeia de entrada, portanto, é texto escrito digitalizado. Já dispomos de um sistema para realizar essa segmentação: o módulo de pré-processamento morfossintático ${ }^{3}$ do

30 pré-processamento morfossintático é realizado pela vinculação on-line do CoGroo, corretor gramatical do LibreOffice, com o DadosSemiotica. Todos os softwares citados são livres e de código aberto, daí a facilidade de integração entre projetos diferentes para obtenção de resultados não previstos inicialmente por nenhum deles. 
DadosSemiotica ${ }^{4}$, software no qual um processo de análise e síntese será realizado nas etapas posteriores ao trabalho apresentado neste artigo (MATTE, 2012), das quais temos uma amostra preliminar no tópico "Análise preliminar de identidades no chat".

As unidades dessa fita são definidas como termos. A supersegmentação em sentenças, necessária à análise da via semiótica, segue o padrão morfossintático definido em Matte et al. (2012). A análise linguística, baseada no mesmo padrão, produz uma segmentação em palavras para determinar as unidades mínimas para a análise da via do código e esta é, segundo a hipótese atual, a unidade mínima da fita de entrada para todas as análises. Uma subsegmentação silábica pode vir a ser necessária para a análise da via do sinal.

A via semiótica sempre trabalhará com unidades iguais ou maiores do que a sentença, o que não impede que as análises, como veremos, busquem, nas palavras, pontos de ruptura produtores de sentido. A análise desta via vai muito além do que seria pertinente analisar no escopo do presente artigo, buscamos então uma análise simplificada apenas para ilustrar alguns dos muitos pontos de ruptura geradores de ruído.

A análise do sinal pode ter, como ponto de partida, a escrita fonológica. 0 programa Setfon (MATTE; MEIRELES; RIBEIRO, 2011) contém um método (baseado em Matte et al., 2006) para transformação do texto escrito em escrita fonológica e produz uma segmentação vowel-to-vowel ( $V$ - $V$ ), necessária à análise fonético acústica a que o programa se propõe, mas que pode ser adotada como base para a subsegmentação e análise do sinal para os propósitos desse trabalho, já que a notação fonológica, baseada em Câmara Jr. (2002a, 2002b,

4 http://dadossemiotica.textolivre.org 
2004), trabalha com metassegmentos e, portanto, não considera variações da manifestação acústica, mas, sim, as possibilidades previstas para essa manifestação, em bloco.

A metodologia aqui proposta visa encontrar o ponto passível de gerar ruído e, portanto, o ponto em que uma regra da análise da cadeia de entrada pode ser alterada tendo em vista a adaptação do sistema aos atores e mensagens envolvidos. Nos exemplos a seguir apresentamos, para cada um, uma análise trecho a trecho da cadeia de entrada e um esquema mostrando em qual das vias a produção do ruído gera necessidade de ajuste.

\section{Exemplos}

Figura 5 - Leitura da sentença "Ontem ele apagou a velhinha" segundo as três vias de comunicação do esquema de Silva (1972).

\begin{tabular}{|c|c|c|c|c|c|}
\hline & Ontem & ele & apagou & a velhinha & . \\
\hline Código & Advérbio & Sujeito & Verbo passado & Objeto & Ponto final \\
\hline Sinal & /oNteIN/ & /elI/ & /apagoU/ & /avelinhA/ & $\begin{array}{l}\text { // (prosódia: } \\
\text { terminativo) }\end{array}$ \\
\hline \multirow[t]{2}{*}{ Semiose } & \multirow[t]{2}{*}{ Passado recente } & \multirow[t]{2}{*}{ Qutrém } & \multirow{2}{*}{$\begin{array}{l}\text { Dupla } \\
\text { possibilidade } \\
\text { isotópica } \\
\text { (assassinato ou } \\
\text { aniversário?) }\end{array}$} & $\begin{array}{l}\text { Apagamento da } \\
\text { velinha }\end{array}$ & \multirow[t]{2}{*}{$\begin{array}{l}\text { Declaração } \\
\text { terminada. }\end{array}$} \\
\hline & & & & $\begin{array}{l}\text { Assassinato da } \\
\text { velhinha }\end{array}$ & \\
\hline
\end{tabular}

Tomemos a frase "Ontem ele apagou a velhinha” (Figura 5).

A Figura 5 mostra as três análises necessárias: a análise do código, a análise do sinal e a análise da semiose (como sentido produzido ou passível de ser produzido). A análise morfossintática apresentada para a via do código está simplificada, pois o processamento gera um resultado para a sentença com elementos em árvore (MATTE, 2012b). No caso desta sentença, o resultado é: 
(S (ADVP (adv-*-ontem Ontem) ) (SUBJ (NP (pronper$\mathrm{s}-\mathrm{M}=3 \mathrm{~S}=\mathrm{NOM}$-ele ele) ) ) (P (VP (vfin-PS=3S=IND-apagar apagou) ) ) (ACC (NP (art-F=S-o a) (n-F=S-velho velhinha) ) ) (PUNCT .) )

Note que cada nome simplificado da análise do código está definido como um ramo na análise morfossintática:

- advérbio: (S (ADVP (adv-*-ontem Ontem) )

- sujeito: (SUBJ (NP (pronpers-M=3S=NOM-ele ele) ) )

- verbo passado: (P (VP (vfin-PS=3S=IND-apagar apagou) ) )

- objeto: (ACC (NP (art-F=S-o a) (n-F=S-velho velhinha) ) )

- ponto final: (PUNCT .) )

A análise do sinal pelo Setfon resulta nos segmentos:

- o'Nt

$\cdot \mathrm{eN}$

- e'l

$\cdot \mathrm{e}$

- Ap

- Ag

- o'U

$\cdot a^{\prime} v$

- elh

$\bullet$ i'nh

$\cdot \mathrm{A}$

Optamos por incluir um ponto na sequência de entrada para deixar determinados os subsegmentos $V$ - $V$ dentro do conjunto composto por eles na expressão.

A análise da via semiótica, simplificada neste artigo, mostra uma possível bifurcação no que tange ao sentido do 
verbo apagar. Trata-se de uma bifurcação isotópica (com respeito a temas e figuras e altamente vinculada à semântica das palavras) que indica que o modelo seria bem representado por uma árvore de decisão pois, dependendo da escolha feita nesse elemento, determina-se um ou outro efeito de sentido.

Semiose é um processo, sinal e código são conjuntos de estados e regras que estão em processo. Nesse exemplo, se a pessoa interpretar a isotopia do aniversário, ela terá entendido algo parcialmente diferente do que foi dito, por mais significante que seja essa diferença. Ao deparar-se com o termo seguinte (velhinha), o leitor pode ter duas reações: perceber a incongruência da escolha realizada e modificá-la, voltando um passo atrás, ou realizar uma leitura em bloco e ignorar a ortografia que diferencia velhinha de velinha (se fosse fala, não haveria diferença perceptível).

No esquema de Silva temos um ruído semiótico passível de acontecer em função de uma homofonia que levaria à leitura em bloco (e não letra a letra) do termo "velhinha", trocando-o por velinha (Figura 6).

Figura 6 - No exemplo 1, o ruído acontece pelo desajuste entre a mensagem a ser comunicada e a mensagem efetivamente comunicada, na via semiótica do esquema.

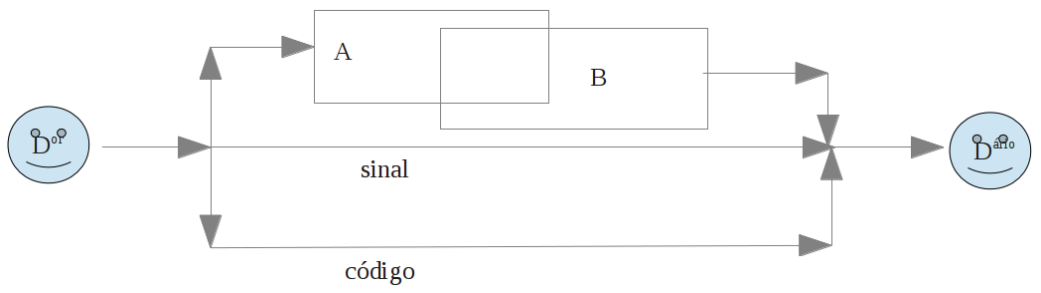

A Figura 6 mostra a intersecção parcial entre os conjuntos A e B, sendo A o que o Destinador queria dizer (contexto 
de assassinato) e B o que o Destinatário pode entender (contexto de aniversário). Sempre que um Destinador fala algo, ele deixa algumas lacunas (não ditos no canal semiótico), presumindo que o Destinatário possa preenchê-las corretamente. Nesse caso, ele não explicou que o contexto específico era o de um assassinato e permitiu ao Destinatário fazer uma escolha diferente de isotopia para a palavra "apagou". 0 exemplo permite perceber que a lacuna mal preenchida no processo de semiose foi causada porque o sinal continha uma quase homofonia (também permitindo a escolha errada) e porque no código nenhuma das escolhas causaria estranheza, pois tratam-se de cadeias aceitas tanto no código que o Destinador presume ser o do Destinatário, quanto no código que o Destinatário presume ser do Destinador.

A frase do exemplo 2 é uma sentença dita por uma criança em fase de aquisição de fala e anotada informalmente: "Um auau!".

A cadeia de entrada para a semiótica precisa ser composta por elementos sintáticos com sentido próprio. Por isso "Um auau" pertence à mesma célula da fita (Figura 7).

Figura 7 - Leitura da sentença “Um auau!”, conforme as três vias de comunicação.

\begin{tabular}{|l|l|l|l|}
\hline \multicolumn{2}{|c|}{ Um auau } & \multicolumn{2}{|c|}{$!$} \\
\hline Código & Demonstrativo/objeto & $\begin{array}{l}\text { Ponto } \\
\text { exclamação }\end{array}$ & \\
\hline Sinal & /uNaUaU/ & $\begin{array}{l}/ \text { (prosódia: } \\
\text { terminativo } \\
\text { exclamativo) }\end{array}$ & \\
\hline Semiose & Adulto: cachorro & $\begin{array}{l}\text { Declaração } \\
\text { terminada com } \\
\text { emoção. }\end{array}$ & \\
\cline { 2 - 4 } & $\begin{array}{l}\text { Criança: classe mais } \\
\text { ampla }\end{array}$ & \\
\hline
\end{tabular}


Sendo quem fala um adulto (Destinador) e quem escuta uma criança (Destinatário) (poderia ser o contrário), o subconjunto correto é menor para o adulto do que para a criança. Daí o espanto esperado no caso de o adulto observar a criança chamando de "auau" a um cavalo, caso em que a lacuna, do ponto de vista do adulto, teria sido mal preenchida (Figura 8).

Figura 8 - Esquema para a sentença “Um auau!". 0 ruído afeta duas das três vias de comunicação.

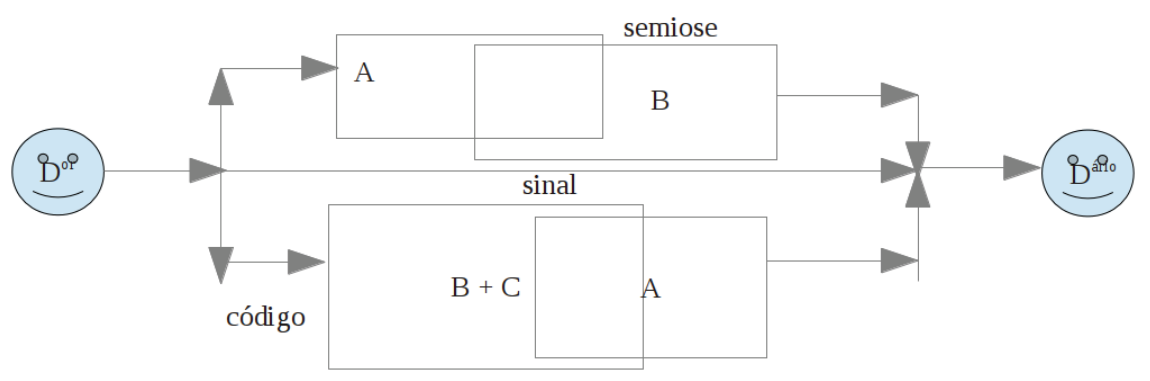

Nesse caso, a lacuna foi mal preenchida porque o vocabulário de um não corresponde ao vocabulário do outro: o ruído que causou o erro de interpretação veio do código. Para o adulto, "auau" corresponde ao conjunto:

$\mathrm{A}=\{$ cachorro $\}=\{$ quadrúpede, rabo, pelo, tamanho limitado, latido\} enquanto para a criança, "auau" corresponde a um conjunto de características menos específico:

$\mathrm{B}=$ \{quadrúpede, rabo, pelo, qualquer tamanho, qualquer som\}

$\mathrm{O}$ cavalo corresponde a $\mathrm{C}$ para o adulto:

$\mathrm{C}=$ \{quadrúpede, rabo, pelo, tamanho grande, relincho\}

Desse modo, cavalo não pertence a $\mathrm{A}$, mas pertence a $\mathrm{B}$.

A palavra "auau", portanto, existe no código comum, mas tem sentidos diferentes nos subcódigos do Destinador e do Destinatário. 
É importante notar que se trata de dois pontos de geração de ruído: o semântico (no código, no sentido da "palavra") e o semiótico (no sentido do texto).

0 próximo exemplo tem como base um relato de experiência de primeiro contato com computador, no qual a sentença "Aperte o botão para enviar", dita pelo instrutor, causou o ato de apertar o botão (hardware) para desligar a máquina.

A reação esperada para "Aperte o botão para enviar" é, por meio da movimentação do mouse, levar o cursor que aparece na tela até a posição do link para o comando (enviar), representado na forma de um botão de máquina, e clicar sobre ele com outro movimento do mouse. Ou seja, não é só o botão que não foi reconhecido pelo usuário leigo, mas também a representação de apertar ou pressionar que, nesse caso, é uma metáfora para "clicar".

Por isso, trata-se novamente de um ruído gerado em dois pontos de não coincidência: o semântico (sentido da palavra "botão", ruído ideológico) e o semiótico (o sentido da sentença na relação entre os sentidos de software e hardware, ruído semiótico).

O último exemplo busca raízes na teoria semiótica, explorando um pouco mais a via semiótica. A sentença do exemplo 4, "Subiu a escada voando.", tem como destinador e destinatário dois adultos, falantes de língua portuguesa, letrados e sem qualquer tipo de dislexia.

Ou seja, nenhum tipo de ruído é esperado nem na via do sinal (a não ser que algum incidente de natureza externa afete o sinal; por exemplo, a frase for escrita na areia e uma onda a apagar parcialmente), nem na via do código.

Mesmo na via semiótica não é esperado um ruído comprometedor, mas o exemplo serve para compreender um outro tipo de ruído, sempre presente, cuja intensidade pode 
eventualmente afetar a comunicação.

- "subiu a escada" $\rightarrow$ tempo passado, direção de baixo para cima, alçar degraus, mudança de estado;

- "voando" $\rightarrow$ aspectualização temporal correspondendo a velocidade.

Enquanto "subiu a escada" significa um percurso que poderia ser descrito como: "apoiou-se num dos pés, colocou o outro pé no primeiro degrau da escada, passou o peso para ele, levantou o pé liberado do peso para o degrau seguinte e assim por diante até alcançar o topo da escada", "voando" indica que isso foi feito rapidamente.

No entanto, voar pode significar algo completamente diferente. Se o sujeito de "subiu" for um bruxo, ou um super-herói, por exemplo, "voando" pode significar "sem tocar os degraus da escada". Assim, mesmo que a frase estivesse sendo lida num contexto de história fantástica e o personagem voasse o tempo todo, um leitor menos atento ao contexto poderia considerar que o conteúdo da expressão "subiu a escada" definia o ato de tocar os degraus e se sobreporia às capacidades sobrenaturais do personagem.

Se o texto for um romance, como comentamos acima, caso o leitor realize interpretações inadequadas, espera-se que esses ruídos sejam corrigidos durante a leitura, mas se o texto é uma conversa num chat, o ruído só será suavizado por alterações e verificações realizadas durante a troca de mensagens pelos participantes, sentença a sentença. Se no primeiro caso a compreensão é dada pelo texto (romance) como um todo dotado de sentido, no segundo caso o todo dotado de sentido é um processo e não um produto final, de modo que, a cada nova intervenção, todo o sistema está sujeito a alterações e os participantes podem, inclusive, reinterpretar outras sentenças escritas antes daquela reveladora do ruído. No 
exemplo abaixo, tomado do próximo tópico, a consulta feita por Papagaio, embora não tivesse o objetivo de verificar o gênero do nick abelha, permitiu a identificação do ruído e consequente adaptação do sistema, possibilitando a reinterpretação de toda a interação anterior ao trecho e modificando o sentido de sua continuação.

[12:41:26] < Papagaio> Oi abelha, quem é o abelha?

[12:42:12] < Gato> Papagaio, eh uma amiga do linux

Dito desta forma há pouca diferença entre participar de um chat ou ler um romance; a grande diferença está no fato de que o chat pressupõe constante troca de papéis entre Destinador e Destinatário e isso, se por um lado torna a análise semiótica mais complexa, por outro lado pode-se dizer que viabiliza a geração automática de diálogos.

Além disso, há que se considerar que, quando um dos atores é um robô, a relação de adaptação e troca de papéis é a mesma do chat (BUZATO, 2010), provavelmente com maior fidelidade num sistema inteligente adaptativo, de modo que a atuação de ambos atores pode e deve ser tratada da mesma forma, como comunicação em processo.

\section{Análise preliminar de identidades no chat}

Para concluir, apresentamos uma breve análise de identidades.

0 corpus foi obtido num chat do IRC ${ }^{5}$, na rede Freeno$\mathrm{de}^{6}$, com logs coletados pelo cliente de IRC Konversation, para Linux (http://konversation.kde.org/). Para manter a privacidade dos usuários, optou-se por trocar seus nicks por nomes

\footnotetext{
5 http://en.wikipedia.org/wiki/Internet_Relay_Chat

6 http://freenode.net
} 
de animais (no caso de nicks compostos em que uma parte foi utilizada anteriormente, optou-se por manter o nome do animal ou parte dele, conforme feito originalmente, acrescentando o aposto original, para não prejudicar a lógica da troca escolhida pelo usuário).

Os dados foram coletados em 4 dias diferentes, não sequenciais, somando 81 horas e 41 minutos de registro. Do número total de entradas (312), 268 correspondem a entradas de texto pelos usuários (a que chamamos "fala") e 28 são notificações de mudanças no nick (troca de nick, entrada e saída), sendo o restante relativo a outros tipos de notificações características deste protocolo de chat. Utilizou-se o programa DadosSemiotica para organizar as análises; o Módulo de Pré-processamento Morfossintático provido por este software dividiu as entradas de texto que continham pontuação e outros indícios de final de sentença, totalizando 348 sentenças para a análise, das quais 305 são sentenças pertencentes a dados fornecidos pelos usuários ("fala").

0 texto foi tratado pelo Módulo de Chat, que forneceu, dentre outras coisas, informações sobre a demora de uma entrada em relação à entrada anteriormente registrada, em minutos, tipo de notificação e nick. A análise manual marcou:

- nick atual: o nick do responsável pela entrada de texto em questão ou o nick sobre o qual refere-se a notificação de entrada, saída ou troca de nick. Se for notificação de saída, recebe valor nulo;

- nick anterior: o nick que o mesmo sujeito tinha na sua última interação; em caso de notificação de entrada, recebe valor nulo;

A identidade no chat também é indicada pela citação de nicks pelos usuários, mas, dado o escopo estrito deste trabalho, estas citações não foram abordadas. 
0 excerto de chat contou com 12 nicks diferentes, conforme o gráfico da Figura 9. 0 código numérico é gerado também automaticamente pelo programa: o DadosSemiotica faz esta conversão para, rodando o R (http://cran.r-project.org/) em background, calcular alguns dados descritivos (média, mediana, desvio padrão e variança) e gerar um histograma da categoria especificada. A relação informada pelo programa sobre a conversão dos nicks para números foi: 1) abelha, 2) “", 3) Gato, 4) Papagaio, 5) Lobinho, 6) vespa_amarela, 7) abelha_ away, 8) Papa_Ja_Volta, 9) Papa_Voltou, 10) Papa_foi_de_novo, 11) Papa_voltou_de_n, 12) gato e 13) Formiga.

Figura 9 - Distribuição das amostras segundo o nick utilizado no momento da interação.

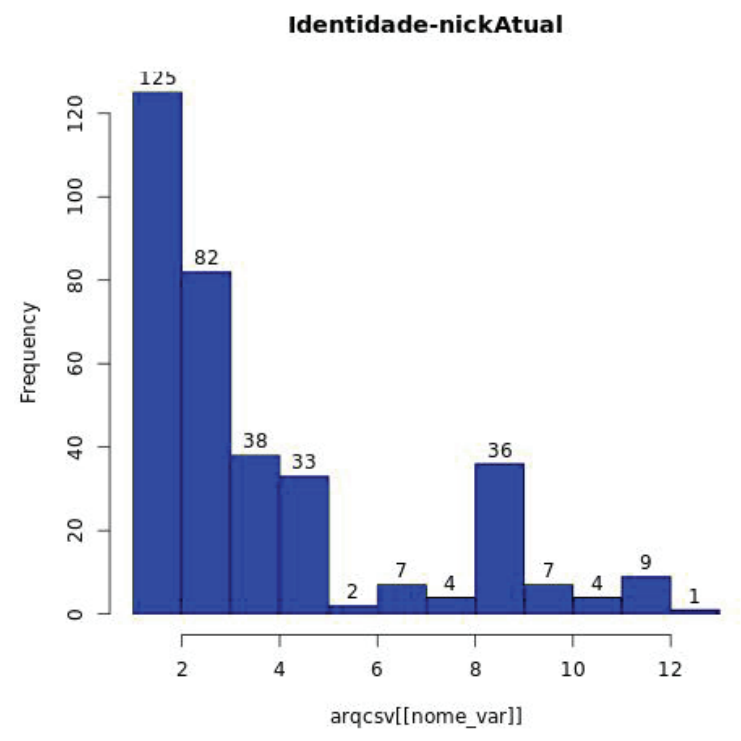

Foram registradas 7 entradas de nicks, 7 saídas e 14 trocas, nas 81 horas de registro, de modo que se pode concluir 
que é um chat frequentado por poucos usuários e a observação dos dados mostra que a maioria permaneceu on-line por muitas horas. Papagaio utilizou 5 nicks diferentes durante o registro, todos eles composições do nick inicial. Gato utilizou o mesmo nick com letra inicial minúscula e abelha também utilizou um segundo nick, composição do primeiro.

0 nick mais ativo foi abelha, que, somando-se sua entrada com o nick composto abelha_away, totalizou 129 intervenções. Os 3 nicks mais utilizados em seguida foram Gato (38 entradas), Papa_Ja_Volta (36 entradas) e Papagaio (33 entradas). A soma das entradas dos nicks utilizados por Papagaio é de 56 entradas e as entradas do Gato (somadas a gato) totalizam 47 manifestações.

Esta amostra apresenta baixa correlação $(0,06$, método de Pearson) entre o tempo de resposta e o tipo de lacuna principal; como se trata de dados sincrônicos mas cuja leitura e resposta pode acontecer aleatoriamente (já que os participantes em geral não estão conectados tendo como objetivo principal sua participação no chat, mas outras atividades on-line e off-line), esse resultado é previsível.

A análise destes dados será feita considerando-se o esquema de comunicação, tendo como objetivo observar a construção de uma identidade no chat, tema para o qual este trabalho apresenta-se como uma pesquisa piloto.

A identidade no chat não é simplesmente um nick: trata-se de uma estrutura complexa, composta principalmente por um ou vários nicks, um estilo de escrita, tipo de interação, assuntos preferidos e frequência de acesso e participação. Podemos pensar essa construção como um autômato que, a cada nova ocorrência, pode adaptar-se e modificar-se. Para cada participante do chat, essas construções são diferentes, pois cada um tem uma experiência particular determinada, inclusi- 
ve, pelas características mesmas de sua própria identidade no chat. Por esse motivo, é adequado pensar que, para análise da construção dessa identidade, é necessário arbitrar um ponto de vista, ou seja, escolher um dos participantes como observador da evolução da identidade dos outros participantes do chat. Este participante pode ser um chatterbot, por exemplo, que colheria os dados do chat, limitado à sua presença on-line; são os limites desta presença que delimitam o contexto de criação das identidades: em outras palavras, não se levanta hipóteses sobre a identidade de um determinado nick se ele só entrar na sala de bate-papo quando o participante observador não estiver nela.

Semioticamente falando, diríamos que só existe um $\mathrm{D}^{\text {or }}$ se ele ocupar esse papel para um $\mathrm{D}^{\text {ário }}$, numa existência de dependência recíproca. Assim, o esquema de comunicação só opera quando houver tal condição satisfeita. Considerandose esta premissa, pode-se assumir que o estado zero do chat passa a existir quando ele é iniciado para o participante que, doravante, chamaremos de Observador.

Sua entrada no chat é registrada pelo programa Konversation da seguinte forma:

[qua 25 abr 2012] [12:37:54] Entrada ( nickObservador@unaffiliated/nickObservador) juntou-se ao canal \#canal.

[qua 25 abr 2012] [12:37:54] Tópico 0 tópico do canal é Canal do grupo XX fale de tudo e todos ao mesmo tempo! Eletrônica, política, carros, programas....

[qua 25 abr 2012] [12:37:54] Tópico 0 tópico foi definido por Lobinho em 06-10-2011 20:16.

[qua 25 abr 2012] [12:37:54] Modo Modos do canal: F, nenhuma cor permitida, não receber mensagens de fora, proteção de tópico 
[qua 25 abr 2012] [12:37:54] Criado Este canal foi criado em 06-10-2011 19:14.

[qua 25 abr 2012] [12:38:07] URL URL do canal: http://www.site.xxx

- Principal lacuna: a partir da análise de outras categorias, também manuais (via do sinal, via do código e via semiótica), cada sentença foi classificada conforme sua principal lacuna (a com maior probabilidade de provocar um ruído relevante para a comunicação) fosse código, semiótica, sinal ou ruído improvável (um cumprimento "oi", por exemplo, no contexto de entrada de um nick, foi considerado como ruído improvável).

Note que estas linhas são visualizadas pelo Observador na interface de acesso do programa quando de sua entrada no canal. Ou seja: o primeiro registro acessado pelo Observador é exatamente o de sua própria entrada no canal (Figura 10).

Figura 10 - Estado zero.

Nick entra no canal

A partir de então, cada nova entrada de texto no chat, seja pelos usuários, seja na forma de uma notificação do sistema, corresponde a uma mudança nesse estado, o qual vai, neste modelo, bifurcar-se com a criação de um clone a cada nova identidade com a qual o Observador interagir. 0 número de variáveis que afeta o desenvolvimento de cada clone é imprevisível, mas vamos procurar aqui nos ater apenas a uma delas. Temos três tipos de ocorrências nesta amostra, com:

Entrada e saída do usuário sem troca de nick: 
- [qua 25 abr 2012] [22:23:04] Entrada Formiga juntouse a este canal ( Formiga@IP.provedor).

- [qua 25 abr 2012] [22:33:40] Sair Formiga deixou este servidor (Ping timeout: 260 seconds).

Troca de nick para nick composto e vice-versa:

- [qua 25 abr 2012] [14:27:08] Apelido Papagaio está conhecido agora como Papa_Ja_Volta.

Troca de capitalização no nick, sem mudança do nick, só registrado neste corpus durante um processo de saída e entrada:

- [qua 25 abr 2012] [16:50:53] Sair Gato deixou este servidor (Quit: Fui embora).

- [qua 25 abr 2012] [19:24:37] Entrada gato juntou-se a este canal ( gato@IP).

Ocultamos os dados de IP e provedor para proteger a identidade do informante. Para fins do presente artigo, vamos nos ater ao primeiro tipo de ocorrência, com o trecho inicial da amostra (nota-se que a última notificação de início de chat, citada acima, ocorreu às 12:38:07, um segundo antes da primeira manifestação dos usuários). A data foi retirada dos trechos seguintes porque os participantes só vêem a hora, não a data, durante o uso do chat; a data fica registrada apenas pelo programa nos logs. As manifestações foram numeradas apenas para referência no presente artigo:

1. $[12: 38: 08]<$ Gato $>$ eee

2. $[12: 38: 15]<$ abelha $>$ :)

3. [12:39:09] <Gato> abelha, como esta o seu projeto?

4. $[12: 40: 44]<$ abelha> qual deles, Gato?

5. [12:41:26] <Papagaio> Oi abelha, quem é o abelha? 
6. $[12: 42: 12]<$ Gato > Papagaio, eh uma amiga do linux

7. $[12: 42: 22]<$ Gato $>$ nao participa da lista

8. [12:42:23] <abelha> oi, Papagaio

9. [12:43:17] * abelha odeia referencias bibliográficas... escrevendo uma ementa :/

10. [12:43:36] < Gato> abelha, o projeto dos servidores

11. [12:43:55] < Gato> lembra q eu te mostrei um link sobre o open hardware

12. [12:44:01] < Gato > desculpa

13. $[12: 44: 04]<$ Gato $>$ open compute

14. [12:44:05] < Lobinho>putz neutro travestido de terra, dificil falar a linguagem da nbr5410 hein..

15. [12:44:53] <Lobinho> boa tarde abelha!!

16. [12:45:08] <abelha> ah, Gato, ta parado, tivemos que parar pra focar num outro projeto mais urgente... pior que daí veio uma avalanche de coisas mais urgentes pegando carona :/

17. [12:45:15] <abelha> oi, Lobinho :)

18. $[12: 45: 49]<$ Lobinho $>$ :)

No excerto acima, o Observador (abelha) é conhecido de um dos integrantes do chat (Gato), que o chamou para aquele canal a partir de outro no qual conversavam, portanto este aguardava a entrada daquele no canal. Caso abelha entrasse num canal desconhecido em que os participantes não esperam sua chegada, a manifestação 1 jamais seria compreendida por abelha como sendo uma recepção para si mesmo. Provavelmente seria recebida como se sua entrada tivesse ocorrido no meio de uma interação entre os outros participantes. Nesse caso, o emoticon (manifestação 2) com o qual abelha respondeu ao Gato teria outro sentido: enquanto aqui "eee" é uma manifestação de boas vindas e o emoticon é um 
agradecimento, no outro contexto possível esse emoticon não seria uma resposta ao "eee", mas um cumprimento simpático, semelhante a "oi, pessoal".

Vamos, portanto, limitar, a duas situações como possibilidades para a interpretação desta brevíssima interação em momento inicial do chat: A) abelha entrou convidada por Gato, ambos frequentadores de um outro chat e B) abelha não conhecia ninguém no chat onde entra pela primeira vez.

Antes de ir para a situação real do chat (cuja compreensão é possível a partir do próprio trecho acima, apesar das informações serem insuficientes para definir o "lugar" de onde vieram abelha e Gato, podendo se tratar até mesmo do espaço de uma única sala física na qual ambos acessassem o chat por computadores diferentes), vamos refletir sobre a opção B.

A expressão "eee" é insuficiente não só para contextualizar um assunto, mas também para definir seu próprio sentido. Isolada, não tem sentido. Poderia ser dita com ironia, sarcasmo, alegria, decepção, dentre outras possíveis paixões. Dado que pode estar veiculando uma mensagem tanto negativa quanto positiva, é até menos elucidativa que o emoticon com o qual abelha lhe responde (um sorriso, se não positivo, no máximo uma ironia, nunca uma decepção). A título de exemplo de análise das categorias de comunicação, para esta sentença foi indicada, como maior lacuna, a semiótica, pois, a despeito da inegável lacuna no código trazendo consigo possibilidade de ruído ideológico, a vagueza da expressão, com pouquíssima informação, cria uma grande possibilidade de que a experiência que se deseja comunicar seja substancialmente diferente da experiência comunicada, como explicado a seguir.

O Observador (na situação B, em que não é esperado), ao entrar no chat e se deparar com esse "eee" imediato, depa- 
ra-se com um conjunto de possibilidades: a irrupção abrupta e sem contexto de uma expressão com inúmeros e contraditórios sentidos possíveis devido a um ruído no canal do sinal, sua própria aparição inesperada no meio: havia uma conversa antes? Se havia, qual o assunto e qual a posição de Gato a respeito? 0 canal estava silencioso demais e Gato ficou feliz com a entrada de um possível interlocutor? Gato é simplesmente alguém que gosta de escrever coisas sem sentido no canal? Nenhuma dessas possibilidades (e mesmo muitas outras aqui não elencadas) poderia ser descartada por abelha apenas com base na manifestação 1 ("eee").

Nota-se que o foco de atenção é o Gato: é sua identidade que está iniciada para abelha, num estado inicial que podemos chamar de estado 1: ao manifestar-se, Gato estimula a geração de uma identidade-Gato ( ${ }^{\text {Gato }}$ ) para o Observador. Isso leva a uma importante constatação: no escopo deste trabalho, e com base na teoria semiótica das paixões, a identidade é construída a partir do próprio sujeito, formada por todo o processo desde a constituição do sujeito semiótico, sendo parte do papel do Observador apenas a etapa de Moralização (GREIMAS, FONTANILLE, 1993).

Durante o trecho citado acima seriam, portanto, criados, para o Observador, mais dois clones identitários (I ${ }^{\text {papagaio }}$ na manifestação 5 e I Zebrinha na manifestação 14). É importante notar que o Observador também possui uma identidade no chat, cuja interação com as outras identidades tem potencial de modificação e sua identidade pode modificar-se a partir dessa interação, mas ela possui um status privilegiado já que, como ponto de referência, não precisa explicar-se a si próprio: isso fica ainda mais claro se admitirmos que o Observador poderia ser um robô. Por isso usamos uma denominação diferenciada, chamando a identidade-abelha de $\mathrm{O}^{\text {abelha }}$. 
Em termos da adaptatividade, trata-se de uma situação que requer do $0^{\text {abelha }}$ uma verificação a fim de permitir diminuir o número de possíveis sentidos para a expressão "eee". É um problema relativo ao código, determinado pelo ruído físico, que, ao eliminar o contexto, provocou uma grande lacuna na via do código, prejudicando a transmissão da experiência. Manter o sentido em aberto impediria a comunicação, excluindo $0^{\text {abelha }}$ do diálogo em curso, pelo menos até que o número e tamanho das lacunas fossem aceitáveis. Aqui já temos o desenho possível da identidade em forma de clone (Figura 11).

Figura 11 - Mapa da interação um a um no chat, desde o início dos registros pelo observador, com um único interlocutor.

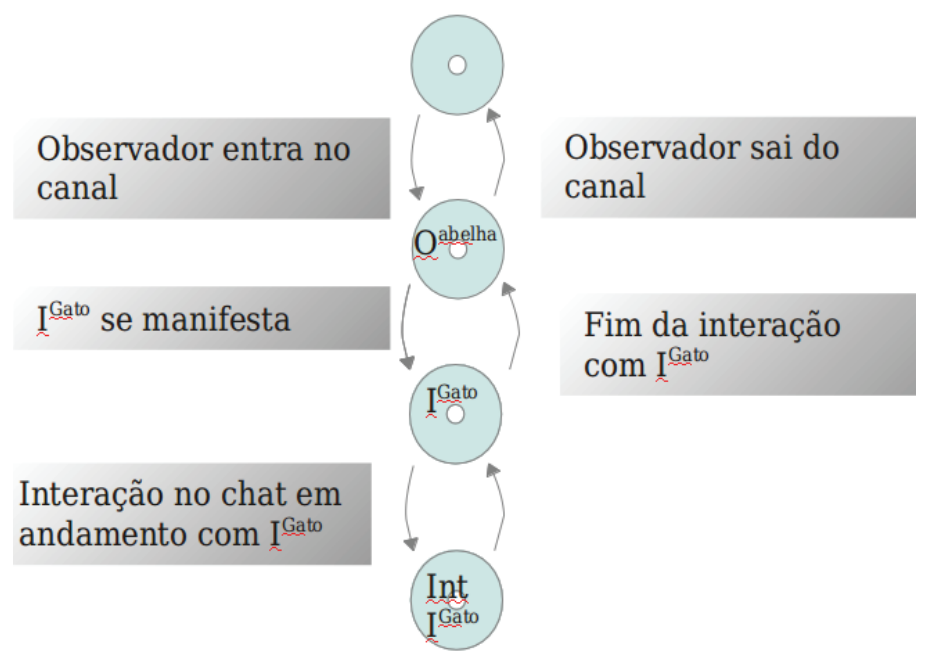

Não cabe aqui insistir nas inúmeras possibilidades decorrentes de tal situação, já que o objetivo é analisar a ocorrência realmente manifestada neste trecho, a opção A, em que Gato convidara abelha a conhecer o canal no qual se desenvolve a interação. É importante apontar, no entanto, que essa 
mudança de perspectiva carrega a manifestação 1 com um sentido específico, diminuindo o ruído físico a ponto de a resposta, expressa pelo $0^{\text {abelha }}$ na manifestação 2 (o emoticon), ser não só adequada como, também, ter sentido suficientemente restrito. Desse modo, a diferença entre a experiência a ser comunicada é muito semelhante à experiência efetivamente comunicada para cada um dos interlocutores. Em outras palavras, a eficiência da comunicação está diretamente ligada à desambiguação, que requer limites claros para a leitura.

Nas manifestações 3 e 4, I ${ }^{\text {Gato }}$ e $0^{\text {abelha }}$ acrescentam, para qualquer participante do chat, a informação sobre esse contexto prévio que os une. Assim, do ponto de vista desse observador, as identidades Ipapagaio na manifestação 5 e I ${ }^{\text {zebrinha }}$ na manifestação 14 são criadas do zero (Figura 12), mas $0^{\text {abelha }} \mathrm{e}^{\text {Gato }}$ já estão mais desenvolvidas, o que só pode ser depreendido de uma análise do conteúdo da interação de 1 a 4.

Nas manifestações 5 a 7, a identidade de Ipapagaio é gerada para o $\mathrm{O}^{\text {abelha }}$ mas, simultaneamente, é incrementada no chat a identidade $0^{\text {abelha }}$ com duas informações: é uma amiga de Gato, de uma comunidade de linux e não está na lista. É curioso que abelha, embora possivelmente não soubesse nada sobre a lista, não tenha perguntado "qual lista" (como fez para o projeto). Sua manifestação 9 mostra que ela não responde à vagueza relativa à "lista", mas responde à negatividade em si desta afirmação "não está na lista", mostrando saber usar os recursos do chat (no caso, um "/me" que ecoa a mensagem diferentemente das mensagens simples que todos estão usando, usado para expressar pensamentos ou dar destaque em algo, uma frase sobre si mesmo pois começa sempre com o nick de quem deu o comando), ou seja: mostra ser novato no canal mas não novato no protocolo de chat usado. E Lobinho usa estratégia semelhante: antes de cumprimentar o recém 
chegado, fala de um assunto que o define no canal e fala isso de forma casual, como alguém que: a) sabe do que está falando e b) não é novato no canal.

Figura 12 - Mapa das identidades dos 3 participantes ativos, do ponto de vista do Observador.

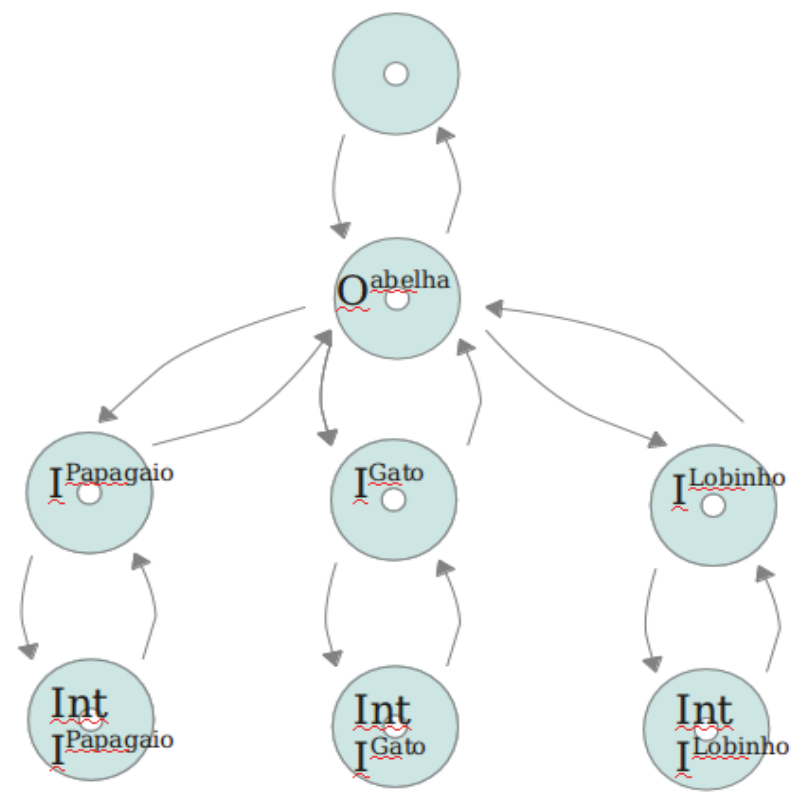

Essas informações incrementam cada uma das identidades no canal para $\mathrm{O}^{\text {abelha }}$ podendo ou não acionar ações adaptativas. Neste pequeno trecho, a interação efetiva em relação aos temas tratados é, de fato, bem pouca: somente acontece entre Gato e abelha, visto que as outras manifestações sobre assuntos que poderiam render longas discussões (isotopia acadêmica na manifestação 9, isotopia técnica de elétrica na manifestação 14) não são desenvolvidos. Uma informação, porém, acarreta uma ação adaptativa que só será sentida em outros momentos do chat: na manifestação 5, Papagaio se 
refere a abelha usando o gênero masculino, o que é imediatamente corrigido por Gato na manifestação 6. No ambiente de IRC o gênero predominante é o masculino, assim ele é a premissa básica: se o nick do sujeito não revelar o contrário, assume-se que seja masculino, mesmo porque não se dispõe de recursos visuais ou sonoros que possam completar a informação sobre o gênero. Assim, o clone inicial é sempre masculino e somente será acionada uma ação adaptativa que modifique, não só a interação a partir de então, mas também toda a memória da interação até ali, se essa decisão não for adequada em algum momento (o que pode acontecer na verificação inicial do gênero do nick ou em qualquer outro momento da interação, como pode nem chegar a acontecer).

Cabe notar que este mesmo trecho ilustrou a exemplificação de um processo de consulta baseado no esquema comunicativo, no final do tópico anterior, e ambas as explicações estão tratando exatamente do mesmo processo: a automodificação do sistema a partir de uma consulta.

0 trecho a seguir, que acontece um pouco mais tarde no mesmo dia, mostra uma discussão sobre troca de nicks.

1. [16:25:28] Apelido Papa_foi_de_novo está conhecido agora como Papa_voltou_de_n.

2. $[16: 25: 39]<$ Gato $>n$ ?

3. $[16: 25: 43]<$ Gato $>$ onde fica?

4. [16:25:43] $<$ Papa_voltou_de_n $>$ de novo :P

5. $[16: 25: 48]<$ Papa_voltou_de_n>nick Papa_Voltou

6. [16:25:50] <Papa_voltou_de_n>ops

7. $[16: 25: 53]<$ Gato $>$ uahuahuahau

8. [16:25:53] Apelido Papa_voltou_de_n está conhecido agora como Papa_Voltou.

9. $[16: 26: 00]<$ Gato $>$ ae

10. [16:26:06] <Gato>Papa_Voltou, Papa_VoltouPapa Voltou 
11. [16:26:12] < Gato>lalala

A lógica da troca de nicks usada pela identidade Ipapagaio baseia-se na sua presença ativa no chat (Figura 11): ele não desconecta, mas espera que o nick acuse se está ou não ativo (em frente ao computador, por exemplo).

Figura 13 - Mudanças de nick na I-Papagaio.

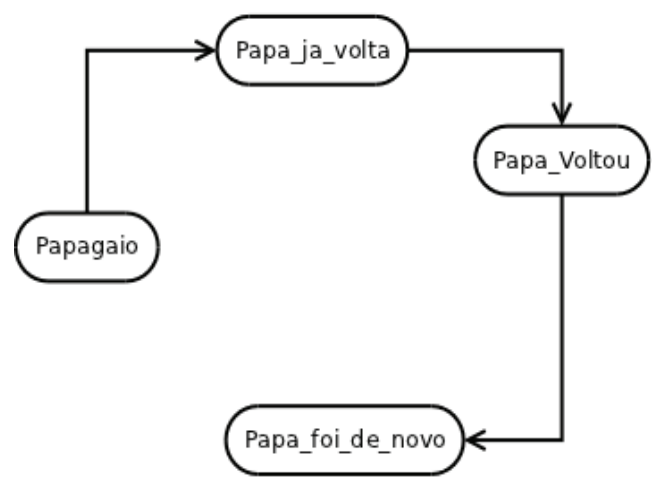

Quando ele muda seu nick de Papa_foi_de_novo para Papa_voltou_de_n, deixa uma lacuna sobre o significado de " $n$ " que, se o interlocutor seguir a lógica proposta pela I ${ }^{\text {papagaio, }}$ será facilmente preenchida: Papagaio está presente novamente no chat, então $\mathrm{n}=$ novo. No entanto, Gato, com base no sentido de "voltar" como deslocamento físico, preenche a lacuna com outro sentido também possível: $\mathrm{n}=$ lugar de onde I $^{\text {papagaio }}$ estaria voltando. Trata-se de um ruído semiótico o qual, sem uma verificação (feita por Gato nas manifestações 20 e 21), permaneceria afetando a compreensão de ${ }^{\text {Gato }}$ sobre a manifestação de I Papagaio.

Isso ilustra nossa hipótese de que o sistema de comunicação proposto precisa exclusivamente de três operações para funcionar: consulta, inclusão e remoção das regras que cada 
um, $\mathrm{D}^{\text {or }}$ e $\mathrm{D}^{\text {ário }}$, usa no processo. Nenhum dos dois actantes é capaz de manter qualquer processo comunicativo sem que essas regras sejam afetadas por estas operações, em maior ou menor escala e em maior ou menor número de vezes. Trata-se de um sistema complexo e dinâmico, portanto, que não pode ser resolvido e nem descrito eficientemente por regras fixas.

\section{Conclusão}

Longe de uma resposta final sobre o tema, procuramos indicar, no presente artigo, a linha reflexiva que pretendemos seguir para um trabalho de geração de diálogos (textualização) na interface entre Semiótica Greimasiana e Tecnologia Adaptativa. Enquanto esta entra como reguladora da relação polarizada entre o destinador e o destinatário, o esquema de comunicação de Silva entra como modelo para indicação de pontos nos quais um ajuste adaptativo se faz necessário a cada intervenção do chatterbot e seu(s) interlocutor(es). As análises do código, do sinal e da semiose são responsáveis por indicar os focos de ruído e, assim, acionar transições adaptativas.

0 artigo procura mostrar que o esquema de comunicação de Silva (1972) é um ótimo candidato a esquema de comunicação adaptativo. A proposta metodológica, no entanto, justamente pela insipiência dessa investida, deve ainda passar por análises de corpora e categorizações semióticas mais finas a fim de se prestar, com maior propriedade, a embasar a produção automática de diálogos prevista no projeto Livrinho. 


\section{Agradecimentos}

O primeiro agradecimento que requer este trabalho é póstumo, a Ignacio Assis Silva, mestre, cujos ensinamentos mobilizam a maior parte das reflexões da autora, e autor do esquema aqui estudado.

Agradecemos com a mesma intensidade a João José Neto quem, desde o WTA2012, vem acompanhando e orientando nossos estudos e ensaios nesse novo campo interdisciplinar que hoje se nos apresenta e quem, por suas inúmeras provocações, figura hoje entre nossas maiores influências.

Esta pesquisa não teria sido possível sem o apoio da FAPEMIG (Processo PPM-00206-10: DadosSemiotica: programa para coleta e análise de dados) e do Grupo de Pesquisa Texto Livre: Linguagem e Tecnologia (http:// dgp.cnpq.br/buscaoperacional/detalhegrupo.jsp?grupo $=0333801$ UBKW6D).

\section{REFERÊNCIAS}

ALFENAS, D. A.; PEREIRA-BARRETTO, M. R. Adaptatividade em Robôs Sociáveis: uma Proposta de um Gerenciador de Diálogos. WTA2012. Disponível em: <http://lta.poli.usp. br/lta/wta/wta-2012/trabalhos/copy6_of_wta2012e09adaptative-search-with-multiple-unmanned-aerial-vehiclesuavs>. Acesso em: 30 jul. 2014.

BARROS, D. L. P. de. "A Comunicação Humana". In: FIORIN, J. L. (Org). Introdução à Lingüística. São Paulo: Contexto, 2002. p. 25-53.

BUZATI, M. E. K. Será que ler um robô desrobotiza um leitor? In: Trab. linguist. apl. [on-line], v. 49, n. 2, 2010. Disponível 
em: $\quad$ <http://www.scielo.br/scielo.php?pid=S0103$18132010000200004 \&$ script=sci_arttext $>$. Acesso em: 12 out. 2012.

CÂMARA Jr., J. M. Dispersos de J. Mattoso Câmara Jr. UCHOA, C. E. F. (Org.). Coleção Dispersos. Nova edição revisada e ampliada. Rio de Janeiro: Lucerna, 2004.

Estrutura da Língua Portuguesa. 35. ed. Petrópolis: Vozes, 2002a.

- Problemas de Linguística Descritiva. 19. ed. Petrópolis: Vozes, 2002b.

GREIMAS, A. J.; FONTANILLE, J. Semiótica das paixões. Tradução de Maria José Coracini. São Paulo: Ática, 1993. p. 155-156.

HJELMSLEV, L. La structure fondamentale du langage. Prolégomènes a une theorie du langage. Tradução de Anne-Marie Lénoard. Paris: Minuit, 1968.

JAKOBSON, R. Lingüística e comunicação. São Paulo: Cultrix, 1969.

KLINKENBERG, J.-M. À quoi servent les schémas? Tabularité et dynamisme linéaire. In: Protée, v. 37, n. 3, 2009.

MATTE, A. C. F. Manual do DadosSemiotica 1.0. 2012. Disponível em: <http://dadossemiotica.textolivre.org/ manual.pdf>. Acesso em: 30 jul. 2014.

- Existe Fala Neutra para a Poesia? DELTA Documentação de Estudos em Lingüística Teórica e Aplicada, v. 24, p. 159-174, 2008a.

. O Processo Semiótico de Comunicação. Sobre o Esquema de Comunicação de Ignacio Assis Silva. In: CASA - Cadernos de Semiótica Aplicada, v. 6, n. 2, dez. de 2008b. Disponível 
em: <http://seer.fclar.unesp.br/casa/article/view/1206>. Acesso em: 12 out. 2012.

. Para uma investigação do padrão prosódico-emocional no Português do Brasil. Pós-doutoramento. Instituto de Estudos da Linguagem da Universidade Estadual de Campinas. Campinas: UNICAMP, 2004a.

Análise Quantitativa da Tensividade no Conteúdo Verbal tendo em vista o Estudo da Expressão da Emoção na Fala e o Modelamento Prosódico. In: Cadernos de Estudos Linguísticos, v. 46, n. 1, p. 53-69, 2004b.

Vozes e Canções Infantis Brasileiras: emoções no tempo. Tese (Doutorado em Semiótica e Linguística Geral) - Faculdade de Filosofia, Letras e Ciências Humanas da Universidade de São Paulo. São Paulo: USP, 2002.

MATTE, A. C. F.; MEIRELES, A. R.; FRAGUAS, C. C. SIL Web analisador fonológico silábico-acentual de texto escrito. Revista de Estudos da Linguagem, v. 14, p. 31-50, 2006.

MATTE, A. C. F.; LARA, G. M. P. Um panorama da semiótica greimasiana. In: Alfa: Revista de Linguística, São José do Rio Preto, v. 53, p. 339-350, 2009.

MATTE, A. C. F.; MEIRELES, A. R.; RIBEIRO, R. T. SETFON: 0 Problema da Análise de Dados Prosódicos, Textuais e Acústicos. In: Revista (con) textos linguísticos, Espírito Santo, v. 1, p. 08-30, 2011.

MATTE, A. C. F.; SILVA, W. D. C. M.; CANALLI, H. L.; RIBEIRO, R. T. DadosSemiotica: coleta e processamento de análises semióticas de texto escrito. In: WORSHOP SOFTWARE LIVRE, 2012. Anais do WSL 2012. Porto Alegre: Sociedade Brasileira de Computação, 2012. v. 1.

NETO, J. J. A small survey of the evolution of Adaptivity 
and Adaptive Technology. WTA2007. Disponível em: $\quad<$ http://ieeexplore.ieee.org/stamp/stamp. jsp?tp=\&arnumber=4445748>. Acesso em: 25 jul. 2014.

NETO, J. J. Adaptive rule-driven devices - general formulation and case study. Revista de Engenharia de Computação e Sistemas Digitais, São Paulo, v. 1, n. 1, p. 45-57, 2003.

. Solving complex problems with Adaptive Automata. In: CIAA'2000 FIFTH INTERNATIONAL CONFERENCE ON IMPLEMENTATION AND APPLICATION OF AUTOMATA, 2001, London, Ontario CANADA. Lecture Notes in Computer Science. New York: Springer Verlag, 2000. v. 2088, p. 340-342. SAUSSURE, F. de. Curso de Lingüística Geral. São Paulo: Cultrix/EDUSP, 1969.

SILVA, I. A. A dêixis pessoal. Tese (Doutorado em Semiótica e Linguística Geral). Faculdade de Filosofia, Letras e Ciências Humanas da Universidade de São Paulo. São Paulo: USP, 1972.

. Figurativização e metamorfose. 0 mito de Narciso. São Paulo: Editora da Universidade Estadual Paulista, 1995.

STOCKINGER, P.; ARNOLD, M.; BOUDON, P.; DESCLÉS, J. P.; RASTIER, F. Intelligence artificielle et théorie sémiolinguistique. Actes Sémiotiques Bulletin, v. VIII, n. 36, 1985. STOCKINGER, P.; DENHIÈRE, G.; FONTANILLE, J.; PIOLAT, A.; ZOCK, M. Intelligence Artificielle, II: Approches cognitives du texte. Actes Sémiotiques Bulletin, v. IX, n. 40, 1986.

Artigo recebido em julho de 2014 e aprovado em novembro de 2014.

Disponível em: http://seer.fclar.unesp.br/casa 